\title{
Microwave-assisted one-pot synthesis of symmetrical dichalcogenides catalyzed by $\mathrm{CuO}$ nanopowder
}

\author{
Giancarlo V. Botteselle $^{a *}$, Marcelo Godoi ${ }^{a}$, Fábio Z. Galetto ${ }^{a, b}$, Devender Singh $^{b}$, \\ Luana Bettanin $^{\mathrm{a}}$ and Antonio Luiz Braga ${ }^{\mathrm{a}}$ \\ ${ }^{a}$ Departamento de Química, Universidade Federal de Santa Catarina, 88040-970, Florianópolis, SC, Brazil. \\ ${ }^{b}$ Departamento de Química, Universidade Federal de Santa Maria, 97105-900, Santa Maria, RS, Brazil. \\ *e-mail:gian.botteselle@hotmail.com
}

Keywords: Organodichalcogenides, Microwave, CuO nano

\section{INTRODUCTION}

Over last few decades, organochalcogen (S, Se and Te) compounds have attracted important roles as reagents and synthetic intermediates in organic synthesis. Organodichalcogenides of sulfur, selenium or tellurium in counterpart of organic peroxides, play an important role in organochalcogen chemistry since they are stable, easy to handle, and reactive enough to produce eletrophilic, nucleophilic and radicophilic species. ${ }^{1}$ In addition showed important biological activities, such as antioxidants and antitumor. ${ }^{2}$

Recently we developed a new methodology to synthesis a wide range of organodiselenides and ditelurides, through cross-coupling reaction of selenium or tellurium and aryl halides using $\mathrm{CuO}$ nanopowder as catalyst. ${ }^{3}$

So we describe here an improved microwaveassisted method to prepare organodiselenides, ditelurides and disulfides using $\mathrm{CuO}$ nanoparticles as catalyst.

\section{RESULTS AND DISCUSSION}

The synthesis of the diaryl/dialkyl dichalcogenides was carried out from the cross-coupling reaction between aryl or alkyl iodides and elemental chalcogens ( $\mathrm{S}, \mathrm{Se}$ and $\mathrm{Te}$ ) in the presence of $\mathrm{KOH}$ (2.0 eq.), catalyzed by $5 \mathrm{~mol} \%$ of $\mathrm{CuO}$ nanopowder in DMSO. The cross-coupling reaction was subjected to microwave irradiation (100W) for $7 \mathrm{~min}$, at $80^{\circ} \mathrm{C}$ (Scheme 1).

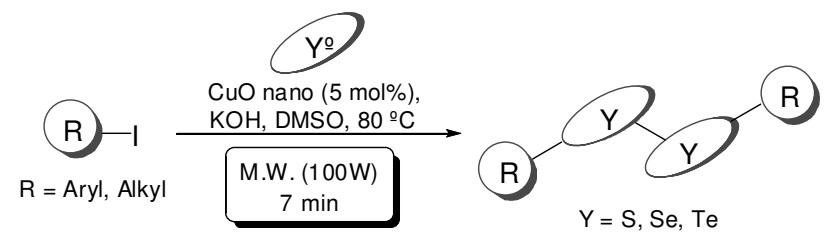

Scheme 1. General Synthesis of Dichalcogenides

This methodology was extended for a variety of iodides 1a-f in the presence of sulfur, selenium or tellurium as summarized in the Table 1 . It is noteworthy that this methodology was efficient to prepare a series of diaryl/dialkyl disulfides 2a-e, diselenides 3a-e and ditellurides 4a-d (Table 1).

Table 1. Synthesis of organodichalcogenides.

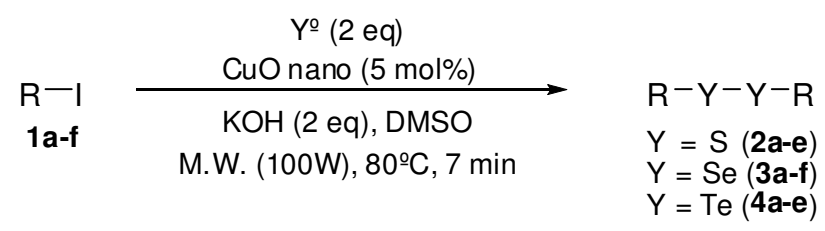

\begin{tabular}{ccccc}
\hline entry & $\mathrm{R}$ & $\mathrm{Y}$ & product & yield (\%) \\
\hline 1 & $\mathrm{Ph} \mathrm{(1a)}$ & $\mathrm{S}$ & $\mathbf{2 a}$ & 67 \\
2 & $4-\mathrm{OMe}(\mathbf{1 b})$ & $\mathrm{S}$ & $\mathbf{2 b}$ & 66 \\
3 & $2-\mathrm{NH}_{2}(\mathbf{1 c})$ & $\mathrm{S}$ & $\mathbf{2 c}$ & 55 \\
4 & $4-\mathrm{Cl}(\mathbf{1 d})$ & $\mathrm{S}$ & $\mathbf{2 d}$ & 50 \\
5 & $n-\mathrm{Bu}(\mathbf{1 e})$ & $\mathrm{S}$ & $\mathbf{2 e}$ & 51 \\
6 & $\mathrm{Ph}(\mathbf{1 a})$ & $\mathrm{Se}$ & $\mathbf{3 a}$ & 70 \\
7 & $4-\mathrm{OMe}(\mathbf{1 b})$ & $\mathrm{Se}$ & $\mathbf{3 b}$ & 76 \\
8 & $2-\mathrm{NH}_{2}(\mathbf{1 c})$ & $\mathrm{Se}$ & $\mathbf{3 c}$ & 61 \\
9 & $4-\mathrm{Cl}(\mathbf{1 d})$ & $\mathrm{Se}$ & $\mathbf{3 d}$ & 85 \\
10 & $n-\mathrm{Bu}(\mathbf{1 e})$ & $\mathrm{Se}$ & $\mathbf{3 e}$ & 55 \\
11 & $3-\mathrm{OMe}(\mathbf{1 f})$ & $\mathrm{Se}$ & $\mathbf{3 f}$ & 94 \\
12 & $\mathrm{Ph}(\mathbf{1 a})$ & $\mathrm{Te}$ & $\mathbf{4 a}$ & 65 \\
13 & $4-\mathrm{OMe}(\mathbf{1 b})$ & $\mathrm{Te}$ & $\mathbf{4 b}$ & 55 \\
14 & $2-\mathrm{NH} \mathrm{H}_{2}(\mathbf{1 c})$ & $\mathrm{Te}$ & $\mathbf{4 c}$ & 54 \\
15 & $4-\mathrm{Cl}(\mathbf{1 d})$ & $\mathrm{Te}$ & $\mathbf{4 d}$ & 45 \\
16 & $n-\mathrm{Bu}(\mathbf{1 e})$ & $\mathrm{Te}$ & $\mathbf{4 e}$ & 50 \\
\hline Isolated $\mathrm{Yields}$ & & &
\end{tabular}

\section{CONCLUSION}

In conclusion, a simple and efficient procedure was developed for the preparation of diaryl/dialkyl disulfides, diselenides and ditellurides. The use of microwave irradiation enables the synthesis of a wide range substituted symmetrical dichalcogenides in just few minutes in moderated to excellent yields.

\section{ACKNOWLEDGEMENTS}

CNPq, CAPES, FAPESC, UFSC and INCT-catálise.

\section{REFERENCES}

${ }^{1}$ Rheinboldt, H. Sulfur-, Selenium-, Tellurium-Compounds, Methoden Org. Chem. (Houben-Weyl) 1967, 9 .

${ }^{2}$ Nogueira, C. W.; Zeni, G.; Rocha, J. B. T. Chem. Rev. 2004, 104, 6255.

${ }^{3}$ Singh, D.; Deobald, A. M.; Camargo, L. R. S.; Tabarelli, G.; Rodrigues, O.

E. D.; Braga, A. L. Org. Lett. 2010, 12, 3288.

$14^{\text {th }}$ Brazilian Meeting on Organic Synthesis - $14^{\text {th }}$ BMOS - September 01-05, 2011-Brasilia, Brazil 